Klaus Krüger (Hrsg.)

Die Inschriften des Stadtgottesackers

in Halle an der Saale (1550-1700) 


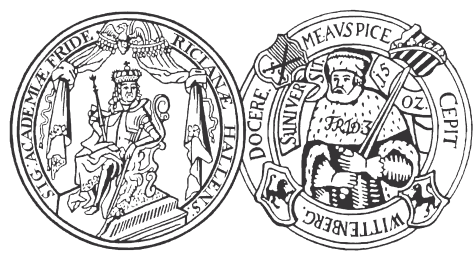

Hallische Beiträge zur Geschichte des Mittelalters und der Frühen Neuzeit Band 12

Herausgegeben von

Andreas Ranft und Andreas Pečar 
Klaus Krüger (Hrsg.)

\section{Die Inschriften des Stadtgottesackers in Halle an der Saale (1550-1700)}

Quellen zum Bürgertum einer Stadt in der frühen Neuzeit

Redaktion: Conny Jakab, Katja Pürschel, Bettina Schröder-Bornkampf

Fotos: Ilja Claus 
Der Band wird gefördert durch einen Druckkostenzuschuss des Stifters Dietrich Moderhack, Braunschweig.

Digitales Zusatzmaterial zu diesem Band:

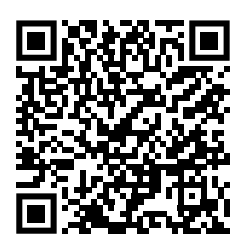

https://www.degruyter.com/view/title/319237

ISBN 978-3-05-006420-8

e-ISBN [PDF] 978-3-11-070014-5

e-ISBN [EPUB] 978-3-11-070021-3

DOI https://doi.org/10.1515/9783110700145

\section{(cc) BY-NC-ND}

Dieses Werk ist lizenziert unter der Creative Commons Attribution-NonCommercialNoDerivatives 4.0 International Lizenz. Weitere Informationen finden Sie unter http://creativecommons.org/licenses/by-nc-nd/4.0/.

\section{Library of Congress Control Number: 2020945651}

\section{Bibliografische Information der Deutsche Nationalbibliothek}

Die Deutsche Nationalbibliothek verzeichnet diese Publikation in der Deutschen Nationalbibliografie; detaillierte bibliografische Daten sind im Internet über http://dnb.dnb.de abrufbar.

(C) 2021 Klaus Krüger, publiziert von Walter de Gruyter GmbH, Berlin/Boston Dieses Buch ist als Open-Access-Publikation verfügbar über www.degruyter.com.

Satz: Meta Systems Publishing \& Printservices GmbH, Wustermark

Druck und Bindung: CPI books GmbH, Leck

www.degruyter.com 